\title{
A Model for Simulating Autoclave-Reactor Pressure Histories
}

RECEIIVEA

MAY 021996

OSTI

\author{
C. B. Thorsness
}

November 1995

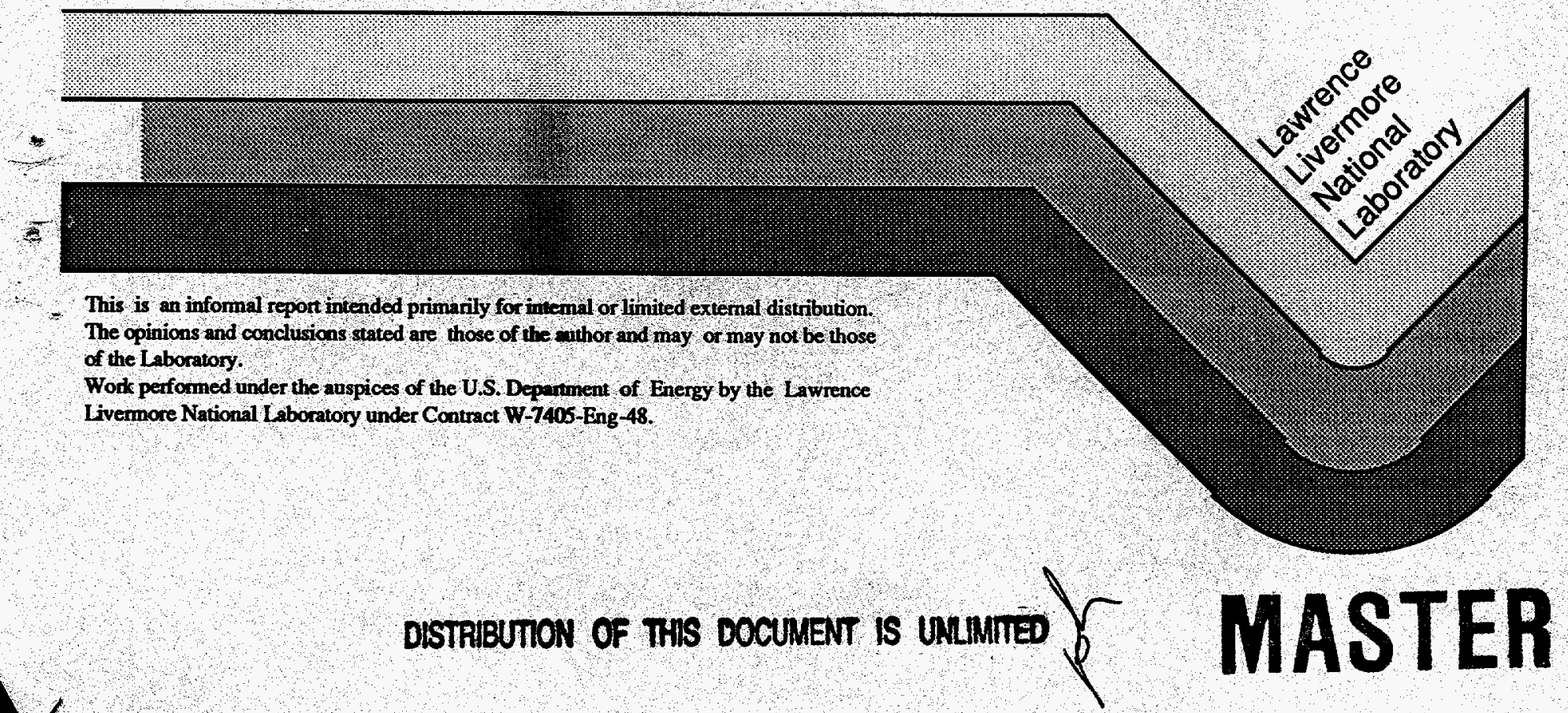




\section{DISCLAIMER}

This document was prepared as an account of work sponsored by an ogency of the United States Government. Neither the United States Government nor the University of California nor any of their employees, mikes any warranty, express or implied, or assumes any legal liablitty or responsibility for the accuracy, completeness, or usefulhess of iny information, apparatus, product, or process disclosed, or represents that its use would not infringe privatel owned rights. $\mathrm{k}$ eference herein to anj specific commerclal products, process, or service by trade name, trodemarl, manufacturer, or otherwise, does not necessarily constitute or Inply its endorsement, recommendation, or tavoring by the United States, Government or the University of Calfornia. The vews and opthions of authors expressed herein do not necessarliy state or reflect those of the United States Government or the University of Californit, and shall not be used for advertising or product endorsement
purposes.

This report has been reproduced directly from the best available copy.

Available to DOE and DOE contractors from the Oince of Scientific and Technical Information P.O. Box 62, Oak Ridge, TN 37831

Prices a valable from (615) 576-8401, FTS 626-8401

Avallable to the public from the

National Technical Information Service

U.S. Department of Commerce

5285 Port Royal Rd.

Springfield, VA 2216 
ABSTRACT …

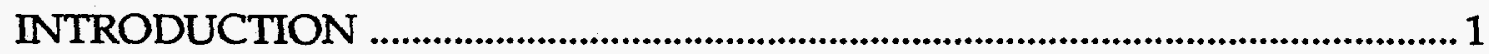

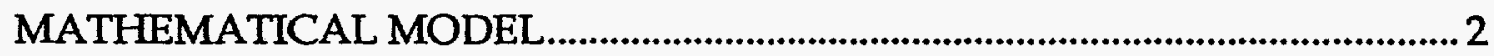

Basic Equations ................................................................................................. 2

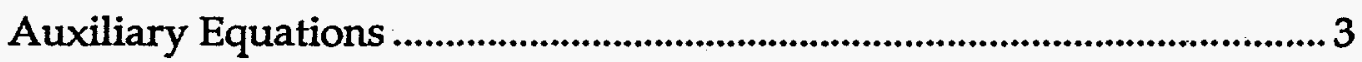

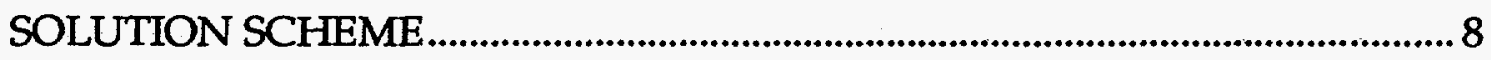

Outline of the Solution Scheme........................................................................... 11

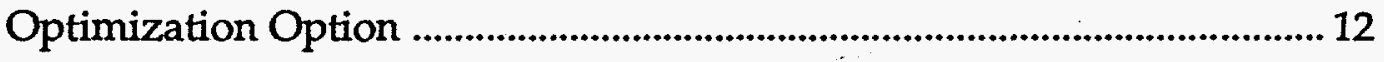

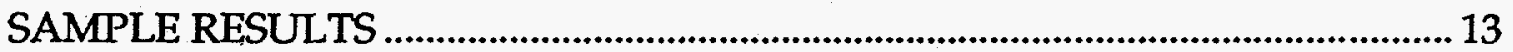

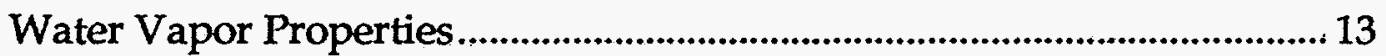

Pure Vapor Liquid Equilibrium Examples...................................................... 14

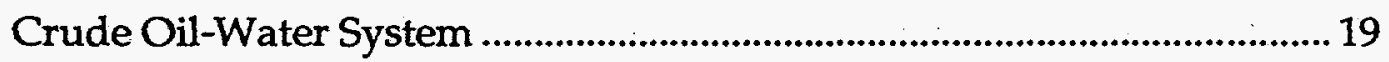

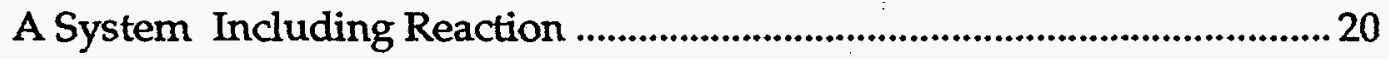

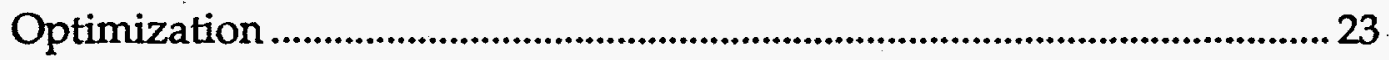

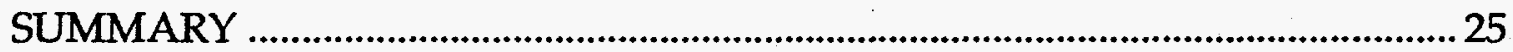

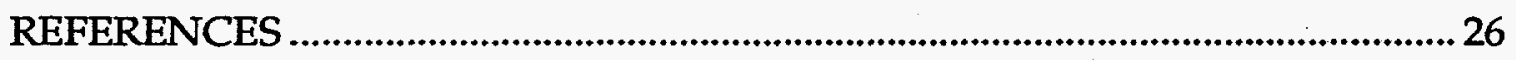

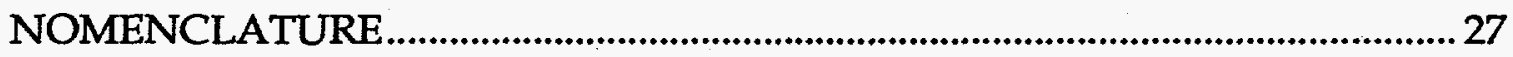




\title{
A MODEL FOR SIMULATING AUTOCLAVE-REACTOR PRESSURE HISTORIES
}

\author{
C.B. Thorsness
}

\begin{abstract}
This report describes a model formulated to simulate well mixed autoclave reactors. The model solves a system of differential and algebraic equations which describe vapor/liquid equilibrium and chemical reactions in the reactor during a heating and cooling cycle. The model allows any number of chemical species to be defined. Phase equilibrium considerations are limited to systems with one liquid and one vapor phase, although some provisions for dealing with a second pure water liquid phase are considered. Equilibrium constraints are formulated using fugacity and activity coefficients. A new version of the general purpose differential-algebraic system solver DASSL, called DASPK, has been used to solve the system of equations. This solver has been found to work well in test problems. Selected results from a number of example problems are described.
\end{abstract}

\section{INTRODUCTION}

Small heated-batch reactors, frequently referred to as autoclave reactors, are often used in developing information for a proposed new chemical/physical processing step. These systems often entail considerable pressure buildup during the course of operation. Usually these closed autoclave systems have a different pressuretemperature relation than the actual proposed process, because of the manner in which generated gas and vapors are handled. A real process may be performed in. a continuous or semi-continuous mode where the vapors and gases are removed from the reaction vessel in a manner and at a rate different from the removal of liquid or solids. Consequently, it is difficult to use the raw pressure data from a sealed autoclave reactor as necessarily indicative of what the pressure requirement of a real system might be. To make estimates for other process conditions it is necessary to have an understanding of the nature of the processes contributing to the pressure buildup in the autoclave system. This understanding can then be translated into other process situations. In addition, it may be that the temperature-pressure history of the autoclave vessel may contain information on chemical reactions occurring inside the autoclave. For these reasons, it is useful to have a computational tool available that can help in analyzing the results of 
autoclave experiments where.a time history of the temperature-pressure behavior is available.

In this report, such a computational tool is described. It involves a mathematical model which allows for phase equilibria to be accounted for in the presence of chemical reactions. The autoclave simulator (ACS) model is implemented as a FORTRAN computer code which accepts as input, initial conditions of the autoclave contents and the temperature-time history of the process. By matching the pressure response curve the model can be used to confirm basic phase equilibria assumptions and/or explore the kinetics of gas releasing/consuming reactions.

In the following the basic mathematical model is described. This is followed by a discussion of the method of computing the various auxiliary parameters needed by the basic model equations. The method of solving the defining equations is then discussed. Finally, a series of example runs using the model to illustrate features and display typical results for systems of interest to the author is discussed.

\section{MATHEMATICAL MODEL}

The mathematical model developed below for describing the evolution of the contents of an autoclave system is quite flexible, but has a number of assumptions and limitations. It assumes that there are no transport limitations within the system, and that the systems of interest consist primarily of two or three phase systems, - a solid phase, a liquid phase and a gas/vapor phase. The model has only limited capability of handling more than one liquid phase and this ability applies to systems in which a water phase and a second immiscible liquid phase are present. The model is formulated to apply vapor-liquid equilibrium constraints to a system of known temperature and total volume with a prevision for handling chemical reactions.

\section{Basic Equations}

The basic equations to be solved are deceptively simple mathematically. Conservation equations are written for each chemical species in the system

$$
\frac{d M_{i}}{d t}=\sum_{n=1}^{n=n_{r}} \alpha_{i n} r_{n},
$$

where $M_{i}$ is the total amount of species $i, t$ is time, $r_{n}$ is the rate of reaction $n$, and $\alpha_{i n}$ is the stoichiometric coefficient of reaction for component $i$, and $n_{r}$ is the number of reactions defined. The equilibrium constraint is imposed on each liquid/vapor species

$$
f_{i}^{V}=f_{i}^{L}
$$


where $f_{i}^{V}$ is the fugacity of liquid/vapor component $i$ in the vapor phase and $f_{i}^{L}$ is the fugacity of liquid/vapor component $i$ in the liquid phase.

The model formulation recognizes 3 basic classes of chemical species: solid species, liquid/vapor species, and permanent gas species. Equation (1) applies to all species, but Eqn. (2) is only applied to liquid/vapor species. The liquid/vapor species are the only ones which may exist both as liquid and vapor.

The primary complexity in the mathematical formulation of the problem revolves around computing the appropriate fugacities and auxiliary variables (e.g. the system pressure). The fugacities have been formulated using gas-phase fugacity coefficients, $\phi_{i}$ 's, and liquid phase activity coefficients, $\gamma_{i}$ 's. The defining equations for fugacities in each phase thus become

$$
\begin{aligned}
& f_{i}^{V}=\phi_{i} y_{i} P, \\
& f_{i}^{L}=\gamma_{i} x_{i} f_{i}^{\circ},
\end{aligned}
$$

where $y_{i}$ and $x_{i}$ are the mole fractions of component $i$ in the vapor and liquid phases respectively, $P$ is the system pressure, and $f_{i}^{\circ}$ is the standard-state fugacity of component $i$. The standard-state fugacity ${ }^{1}$ is defined in terms of the pure component vapor pressure, $P_{v i i}$, at the system temperature by

$$
f_{i}^{\circ}=P_{v p i} \phi_{i}^{s} \exp \int_{P_{v p i}}^{P} \frac{V_{i}^{L}}{R T} d P,
$$

where $\phi_{i}^{s}$ is the fugacity coefficient of component $i$ at saturation at the temperature of interest, $V_{i}^{L}$ is the molar volume of liquid component $i, R$ is the gas constant, and $T$ is the system temperature.

\section{Auxiliary Equations}

It is difficult to completely separate a discussion of the auxiliary equations needed to solve the basic set of equations and the method and implementation of the solution scheme which is embodied in the actual computer model. However, this section attempts to focus on the mathematical formulation, leaving a discussion of the solution scheme for a later section.

Fugacity coefficients. Equation (3), above, requires that a method of determining the fugacity coefficient of each vapor species be available. The current model allows either of two basic assumptions to be made. The first is the trivial case where the vapor phase is assumed to be ideal and thus the fugacity coefficient for all species is simply unity. The other basic approach is to assume that a cubic equation of state (EOS) can be 
defined for each species in the vapor phase. The following illustrates this approach assuming the simple Redlich-Kwong (RK) EOS applies. The equations are basically those given by Reid, Prauznitz and Sherwood ${ }^{1}$ and Reid, Prauznitz and Poling 2 . The RK-EOS for a pure component is

$$
P=\frac{R T}{V-b}-\frac{a}{T^{0.5} V(V+b)}
$$

where $a$ and $b$ are constants given by

$$
\begin{aligned}
& a=\frac{0.427 R^{2} T_{c}^{2.5}}{P_{c}}, \\
& b=\frac{0.0866 R T_{c}}{P_{c}} .
\end{aligned}
$$

The subscripted variables are the critical temperature and pressure of the species of interest. Using Eqn. (6) the compressibility, $\mathrm{Z}$, can be found from its definition, assuming $T$ and $V$ are known,

$$
Z=\frac{P V}{R T}
$$

Eqn. (6) has been extended to mixtures by defining mixing rules that allow mixture critical pressures and temperatures to be computed. A simple mixing rule yields

$$
\begin{gathered}
T_{c_{m}}=\left\{\frac{\left[\sum_{i} y_{i}\left(\frac{T_{c_{i}}^{5 / 2}}{P_{c_{i}}}\right)^{1 / 2}\right.}{\sum_{i} y_{i}\left(\frac{T_{c_{i}}}{P_{c_{i}}}\right)}\right\}^{2}, \\
P_{c_{m}}=\frac{T_{c_{m}}}{\sum_{i} y_{i}\left(\frac{T_{c_{i}}}{P_{c_{i}}}\right)} .
\end{gathered}
$$

The fugacity coefficient for each component can then be defined in terms of mixture and component parameters as 


$$
\ln \varphi_{i}=\ln \frac{V}{V-b}+\frac{b_{i}}{V-b}-\ln Z+\frac{a b_{i}}{b^{2} R T^{1.5}}\left(\ln \frac{V+b}{V}-\frac{b}{V+b}\right)-\frac{2 \sum_{j} y_{j} a_{i j}}{b R T^{1.5}} \ln \left(\frac{V+b}{V}\right)
$$

In this equation the unsubscripted parameters refer to mixture parameters and $a_{i j}$ is defined by

$$
a_{i j}=\left(a_{i} a_{j}\right)^{0.5} .
$$

In addition to the component fugacity coefficients at the system conditions, it is also necessary to compute the pure component fugacity coefficients, $\phi_{i}^{s}$, at saturation at the temperature of the system for use in Eqn. (5). In order to do this, the compressibility, $Z$, must be known. In this case $P$ is known but not $V$. As a result, using Eqns. (6-9) to determine the compressibility factor is more difficult because Eqn. (6) is an implicit rather than explicit equation for the unknown volume. Common practice is to recast Eqns. (6-9), as a cubic equation in compressibility

$$
\begin{gathered}
Z^{3}-Z^{2}+\left(A^{*}-B^{* 2}-B\right) Z-A^{*} B^{*}=0 \\
A^{*}=\frac{a P}{R^{2} T^{2.5}} \\
B^{*}=\frac{b P}{R T} .
\end{gathered}
$$

With $\mathrm{Z}$ and $\mathrm{V}$ in hand, the fugacity coefficient for the saturated vapor of pure component $i$ becomes

$$
\ln \varphi_{i}^{s}=\ln \frac{V}{V-b_{i}}+\frac{b_{i}}{V-b_{i}}-\ln Z-\frac{a_{i}}{b_{i} R T^{1.5}}\left(\ln \frac{V+b_{i}}{V}+\frac{b_{i}}{V+b_{i}}\right) .
$$

Vapor Pressure. Vapor pressures of liquids, required by Eqn. (5), are computed in several ways. Because many of the systems of interest contain water, and its vapor pressure is often the primary contributor to the overall system pressure, a tabular lookup is used. This is based on steam table ${ }^{4}$ values at each degree Celsius up to the critical temperature. A simple linear extrapolation beyond the critical point is used for cases in which the artificial vapor pressure above the critical point is needed.

Two other general correlations of vapor pressure can be employed for other components, the Antoine correlation and a simple corresponding-states approach based on the critical temperature and normal boiling point. The Antoine correlation is given by 


$$
\ln P_{v p}=\mathcal{A} \cdot \frac{\mathcal{B}}{T+C},
$$

where $\mathcal{A}, \mathcal{B}$, and $C$ are constants specific to a given components and the units must be those of the tabulated correlation, generally these are millimeters of mercury for the vapor pressure and degrees $\mathrm{K}$ for the temperature. The critical temperature/boiling point correlation is

$$
\ln P_{v p}=\left(T_{b_{r}} \frac{\ln P_{c}}{1-T_{b_{r}}}\right)\left(1-\frac{1}{T_{r}}\right),
$$

where the $r$ subscripts refer to reduced temperature, which is the ratio of temperature to the critical temperature of the component. In this relation the pressures must be expressed in atmospheres.

Henry's Law Components. The ACS model has the ability to designate components as Henry's law components. The use of Henry's law is appropriate for systems in which gases well above their critical points are present. Henry's law allows solubility of these gases in a liquid phase to be estimated. In this case the liquid phase fugacity calculation, Eqn. (4) is replaced by

$$
f_{i}^{L}=x_{i} H_{i},
$$

where $H_{i}$ is the Henry's law constant appropriate to the system of interest.

Liquid Activity Coefficients. Two methods of computing liquid activity coefficients are available in the model. The first is simply to assume ideal behavior, which implies that all the $\gamma_{i}^{\prime}$ 's are equal to unity. The other involves a simple ideal solution theory model, often called the Hilderbrand-Scatchard model, which is defined by the following equation set for the case in which all binary interaction parameters are assumed zero

where,

$$
R T \ln \gamma_{i}=V_{i}^{L}\left(\delta_{i}-\bar{\delta}\right)
$$

$$
\begin{aligned}
& \bar{\delta}=\sum_{i} \Phi_{i} \delta_{i} \\
& \Phi_{i}=\frac{x_{i} V_{k}^{L}}{\sum_{k} x_{k} V_{k}^{L}}, \\
& \delta_{i}=\left(\frac{\Delta U_{i}}{V_{i}^{L}}\right)
\end{aligned}
$$


Here $\Delta U_{i}$ is the energy required isothermally to evaporate liquid $i$ from saturated liquid to ideal gas. This can be approximated away from the critical point by

$$
\Delta U_{i}=\Delta H_{v_{i}}-R T,
$$

where $\Delta H_{v_{i}}$ is the molar enthalpy of vaporization of pure liquid $i$ at temperature $T$.

Water Solubility. As mentioned above, a basic assumption made by the model is that one liquid phase is present and consequently the liquid activity coefficient estimates described above apply in a straightforward manner. However, a special case in which two phases exist is handled by the model. The system of interest is associated with petroleum applications where water is present. It is often useful to think of these systems in terms of a pure water phase, since hydrocarbons are only sparingly soluble in water, and an organic phase. It often happens that the water solubility in the organic phase is not negligible. This case is treated in the following simplified fashion by the model. The solubility of water in the primary organic liquid phase is computed based on a simple water-solubility-in-organic-phase versus temperature table. In those cases where the water is not entirely soluble, in the water a free-water phase exists and the computations of phase equilibrium proceeds in a straightforward manner. This results from the fact that the free water and the dissolved water are assumed to be in equilibrium, thus only the free water need be considered in computing the liquid fugacity of water for use in the phase equilibrium Eqn. (2).

However, in the case where all the liquid-phase water present is soluble in the organic phase some method of estimating an activity coefficient for the water is necessary. The general simple solution theory is inadequate since it does not correctly predict the activity coefficient at the point of full water saturation of the organic phase which must be given by

$$
\gamma_{1}=\frac{1}{x_{1}}
$$

where the index one is water. For conditions below saturation the following simple relation is incorporated into the model

$$
\gamma_{1}=\frac{1}{\left(x_{1}^{s}\right)^{\alpha_{s}} x_{1}^{1-\alpha_{s}}}
$$

where $x_{1}^{s}$ is the water mole fraction at saturation at the temperature of interest and $\alpha_{s}$ is a parameter. For $\alpha_{s}$ equal to one, the activity coefficient is assumed constant. The activity coefficient probably increases with decreasing water content and this effect can be approximated by using a value of $\alpha_{s}$ less than one. For example, for $\alpha_{s}=1 / 2$ and $x_{1}=x_{1}^{s} / 2$ the computed liquid phase fugacity would be $141 \%$ of its value at $x_{1}=x_{1}^{s}$. 
Enthlapy of Vaporization. The molar enthalpy of vaporization of pure liquid $i$ at a specified temperature is estimated using the Pitzer acentric factor correlation

$$
\frac{\Delta H_{v_{i}}}{R T_{c_{i}}}=7.08\left(1-T_{r}\right)^{0.354}+10.95 \omega_{i}\left(1-T_{r}\right)^{0.456} \text {, }
$$

where $\omega_{i}$ is Pitzer's acentric factor for component $i$.

Liquid Densities and Vapor Volume. The model assumes that densities of liquid components are given by temperature density tables. Component molar densities are assumed to be independent of composition and pressure. The volume of the vapor space at a given condition is assumed given simply by subtracting the solid and liquid phase volumes, $v_{T}$ and $v_{L}$ respectively, from the total volume

$$
\begin{gathered}
v_{V}=v_{T}-v_{S}-v_{L}, \\
v_{S}=\sum_{k}\left(\frac{M_{k}}{\rho_{k}}\right), \\
v_{L}=\sum_{i}\left[\frac{\left(1-Y_{v_{i}}\right) M_{i} m_{w_{i}}}{\rho_{i}}\right],
\end{gathered}
$$

the summation on $k$ is over the solid component indexes and the summation on $i$ is over the liquid/vapor components. The rho's are the densities, $Y_{v_{i}}$ the molar vapor fraction of species $i$, and $m_{w_{i}}$ is the mass of component $i$ per mole. The amount of solids are assumed given in mass units while those for liquid/vapor components are assumed given in mole units.

Reaction Rates. Reaction rates currently in the model are based on simple first order Arrhenius behavior. The rates are specified through the use of an activation temperature, a pre-exponential factor, the reacting component, and the stoichiometry.

\section{SOLUTION SCHEME}

As stated above the basic equations to be solved are represented by Eqns. (1) and (2). The mass balance equations, Eqn. (1), explicitly contains one group of problem unknowns, the component amounts. The second set of unknowns does not appear explicitly in either equation. Although the final system of equations can be formulated in various ways, the ACS model assumes the basic remaining set of unknowns is the fraction of each liquid/vapor component that is in each phase. Since the model deals 
with only one liquid and one vapor phase, only a single fraction, either vapor or liquid, is required for each component. The vapor fraction has been used in formulating the solution scheme.

The model has been formulated to solve systems with an arbitrary number of components of each type and to allow reactions to convert one component to another. As a consequence, the solution scheme must be able to handle the general case. Thus the problem has been viewed as one in which there are $2 n_{L V}+n_{s}+n_{G}$ unknowns, where $n_{L V}$ is the number of liquid/vapor components, $n_{s}$ are the number of solid components and $n_{G}$ are the number of permanent gases. For each of the liquid/vapor components an algebraic equation, Eqn. (2), is written. The remaining $n_{L V}+n_{S}+n_{G}$ equations are ordinary differential equations (ODE's) for the total component amounts, Eqn. (1). This yields a mixed differential/algebraic equation (DAE) system to be solved. Clearly no analytical solution exists to the general problem and thus numerical means must be utilized. DAE systems are in general more difficult to solve than straight algebraic or ODE systems. Fortunately, general purpose software exists which is tailored for such problems. One such software package is called DASSL and is described in reference (4). A version of DASSL has been used to solve the DAE system described here.

One problem often encountered in solving DAE's is specifying a consistent set of initial conditions. In the DAE system considered here the problem manifests itself in the following manner. For any system, initial values of the total amount of each component can be specified, however the other required initial conditions, the vapor fractions, are not easily determined for the general case. The original DASSL package can assist in establishing consistent initial conditions but for the current problem it failed in a number of cases. However, a new method of computing consistent initial conditions has recently been formulated by Brown, Hindmarsh and Petzold 5 , and a version of the software, called DASPK, has been incorporated into the current FORTRAN code. This has worked without fail in test problems run to date.

In solving the DAE system the DASPK software requires computation of residual values for a given set of dependent variables and their time derivatives. The required residual values are constructed form Eqns. (1) and (2) by moving all the terms to one side of the equal sign and equating the resulting expressions to a vector of residual values. For a set of dependent variables which is a solution to the system the residuals will all be zero, for any other sets some or all the residuals will be nonzero. Because of the methods of solution used by DASPK it is important that as smooth as possible a behavior of the residuals with respect to dependent values is maintained. In the current system two problems arise related to the continuity of the residuals which need special attention.

The first of these has to do with the possibility of the disappearance of the liquid phase for a particular component. In this case, Eqn. (2) cannot be directly applied since no liquid exists. One method to handle this would be to sense when the liquid phase of a 
component was about to disappear. The solution could be stopped and the problem reformulated removing the appropriate vapor fraction, and one application of Eqn. (2), from the DAE system. This would be a very awkward procedure and very difficult to implement since the solution would also have to sense when the liquid phase was about to reappear. A more robust, and simpler, solution to this problem, suggested by Hindmarsh 6 , involves the following. The residual equations for Eqn. (2) have the simple form

$$
R_{i}=f_{i}^{L}-f_{i}^{V} .
$$

This equation is replaced with the following

$$
R_{i}=\min \left[f_{i}^{L}, f_{i}^{V}\left\langle Y_{v_{i}}=1\right\rangle\right]-f_{i}^{V},
$$

where the vapor fugacity is viewed as a function of the vapor fraction dependent variable, which is limited to a maximum value of one. This formulation effectively. limits the solution to a vapor fraction of one in a suitably smooth fashion. It does require some extra computation for the vapor fugacity but the fugacity at a vapor fraction of one need only be computed when the solution is sufficiently close to one. In the current scheme this value is only computed if the vapor fraction of a component is greater than 0.9. This has sufficed in all problems run to date.

The second difficulty arises when a vapor/liquid component is completely absent at some point in the calculation. This can happen because a component initially present is consumed by a reaction, or it may occur because a component is not present in the initial system but appears during the course of the calculation because it is the produced by a reaction. In this case, there is no vapor fraction defined for the component which does not exist and blind application of Eqn. (2) for the component can lead to arbitrary values of the vapor fraction satisfying the equation. In fact, depending on the details of the manner in which the coding for computing fugacities is implemented it may be that any value will satisfy the equation. However, this circumstance is not acceptable from the standpoint of the DASPK solution scheme since DASPK would be unable to compute appropriate error estimates and would halt the solution. Removal of the component and its corresponding residual equations would be one solution but, as with the disappearance of the liquid phase this would be difficult to implement.

As before, the scheme chosen to deal with this problem involves retaining all equations. This leads to the problem of suitably defining the value of the computed vapor fraction of a component near the zero. Since the vapor fraction can take on any value as the first trace of a component appears, depending on the state of the system, it is best if the arbitrary vapor fraction computed when the component is not present take on the value it will have when the first trace appears. This notion has been used with success in test problems to date. It has been implemented by evaluating the residual for Eqn. (2) for all components which do not currently exist (i.e. that have $M_{i}$ equal to zero) for the case 
when a epsilon trace amount is assumed to exist. The epsilon amount used on test cases to date has been set at $\sim 10^{-14} \mathrm{~mol}$.

\section{Outline of the Solution Scheme}

The problem of solving the system of equations represented by Eqns. (1) \& (2) using DASPK is essentially one of computing the necessary residuals for these equations at requested values of the dependent variables and their time derivatives. Thus, in terms of computing auxiliary variables it can be assumed that the time, all values of the dependent variables and their time derivatives are given. The following is an outline of the steps followed in computing the required residuals.

First, the system temperature is established at the desired time by linear interpolation in an input table. The reaction rates are then computed and source/sink terms established. This allows the residuals associated with Eqn. (1) to be computed.

Computing the residuals associated with Eqn. (2), the equilibrium constraints, are considerably more complicated. First the vapor and liquid volumes are computed using Eqns. (29-31). Next the vapor phase molar volume is computed based on the computed vapor volume and values of the dependent variables. Gas and liquid mole fractions are also computed. Next the system pressure and compressibility are computed using Eqn.(6-11) for nonideal systems. For the assumption of ideal behavior these equations collapse into the simple ideal gas equation. The gas phase fugacity coefficients are then computed for each vapor/liquid component using Eqn. (12). With the fugacity coefficients, the gas mole fractions and the system pressure in hand Eqn. (3) is then used to compute the gas phase fugacity of each vapor/liquid component.

Next the liquid phase activity coefficients, along with the possible presence of a freewater phase, are determined. Two separate cases are considered, one in which the possibility of a free-water phase is to be considered and one in which it is assumed only one liquid phase is present regardless of the water content.

For the case in which the presence of a free-water phase is to be considered, the maximum water solubility is determined by linear interpolation of an input table of temperature and weight fraction water. Based on this saturation value and the current liquid mole fractions the presence or absence of a free-water phase is determined. If a free-water phase exists then the activity coefficient for water is not needed. Mole fractions of liquid components in the non free-water phase are then determined for use in the liquid fugacity computations of nonwater components. If the water content is below saturation the water activity coefficient is determined using Eqn. (27). The activity coefficients of the remaining liquid components are then set using Eqns.(21-25) for the nonideal case or set to one if ideal behavior is being assumed.

For the one liquid phase case, all activity coefficients are computed based on Eqns. (2125) for the nonideal case, or are set to one for the ideal case. 
Next the standard-state fugacity, defined by Eqn. (5), of each vapor/liquid component is computed. This starts by determining the vapor pressures for each component using either a table lookup, for the case of water, or Eqn. (18) or (19). Next the vapor fugacity coefficient of each component at saturation at the system temperature is computed. If the vapor system is treated as ideal the fugacity coefficient is simply one. In the case when a nonideal system is considered, the computations proceed as follows. First the compressibility coefficient for the pure vapor at the system temperature and component vapor pressure is obtained by solving the cubic equation given by Eqn. (14). This equation in theory holds for liquid and vapor phases, but the phase of interest here is the vapor phase. Consequently, the largest real root of Eqn.(14) is chosen as the desired compressibility factor. This compressibility coefficient is then substituted into Eqn. (17) which yields the desired fugacity coefficient. Finally, the Poynting factor, the exponential factor in Eqn. (5), is approximated. This factor, nearly always near one, is approximated by assuming a constant value for the molar volume.

Finally, the liquid phase fugacity of each vapor/liquid component is computed using Eqn. (4) for all non-Henry's law components. For those components designated as obeying Henry's law, Eqn.(20) is used to obtain the liquid phase fugacity. The Henry's law constant is assumed to be only a function of system temperature and is obtained by linearly interpolating in an input table of values.

With all liquid and vapor fugacities computed the residuals associated with Eqn. (2) can then be computed. This residual computation is modified as outlined above for components which exist in very small amounts or for components in which the current vapor fraction is sufficiently close to unity.

The DASPK solution scheme requires the Jacobian matrix of the residuals with respect to the dependent variables to be computed. Because of the complexity of the algebraic manipulations used to define the residuals the option within the DASPK solver which computes the Jacobian automatically using difference quotients has been chosen. Since no banding of the Jacobian is present the full dense solution scheme is used.

\section{Optimization Option}

Since the primary use of the model is to fit experimental data, an optimization option has been built into the model. This allows many of the model parameters, e.g. kinetic parameters, to be obtained using an algorithm which minimizes an error norm. The error norm has been defined as the sum of the absolute pressure difference between computed and measured pressures divided by the number of data points. The minimization allows any number of parameters to be searched simultaneously. For one dimensional (i.e. for one parameter) minimization a bracketing technique followed by an application of Brent's method ${ }^{7}$ is used. Powell's method as described in reference (7) is used for multidimensional optimizations. 


\section{SAMPLE RESULTS}

In this section a number of sample results are given. These examples are meant to illustrate the types of problems which ACS can examine as well as point out features and limitations of the model.

\section{Water Vapor Properties}

In many of the systems of interest water is an important component. As stated previously, the vapor pressure of water is often a prime contributor to the overall system pressure and consequently a table for water-vapor pressure has been included in the ACS model. However, the ideal gas law or Redlich-Kwong EOS is used for other calculations involving water vapor. The compressibility factor, which leads to specific volume values, is computed either from the ideal gas law or the Redlich-Kwong EOS. In Table 1, the compressibility factor for water vapor is compared to the value computed using the simple Redlich-Kwong EOS. The EOS does a better job than the ideal gas law at the higher pressures. As the pressure/temperature approaches the critical point $\left(22 \mathrm{MPa} / 374{ }^{\circ} \mathrm{C}\right.$ ) the EOS over-predicts the compressibility factor and thus the vapor density. This table is for a pure water system at saturation and does not necessarily reflect differences associated with water vapor under other conditions.

Table 1. Compressibility factors for saturated water vapor from steam table ${ }^{3}$ and computed using the RedlichKwong EOS.

\begin{tabular}{|ccccc|}
\hline & \multicolumn{3}{c}{ Steam Table } & ACS (EOS) \\
\cline { 2 - 5 } Temperature & $\begin{array}{c}\text { Vapor } \\
\text { Pressure } \\
\text { (C) }\end{array}$ & $\begin{array}{c}\text { Specific } \\
\text { Volume } \\
\left(\mathrm{Mg} / \mathrm{m}^{3}\right)\end{array}$ & $\begin{array}{c}\text { Compressibility } \\
\text { Compressibility } \\
\text { Factor }\end{array}$ & $\begin{array}{c}\text { Factor } \\
Z\end{array}$ \\
\hline 25 & 0.00317 & 43.4 & 1.00 & 1.00 \\
50 & 0.01234 & 12.04 & 1.00 & 1.00 \\
75 & 0.03856 & 4.133 & 0.99 & 1.00 \\
100 & 0.1013 & 1.673 & 0.98 & 0.99 \\
125 & 0.2321 & 0.7704 & 0.97 & 0.99 \\
150 & 0.4757 & 0.3926 & 0.96 & 0.98 \\
175 & 0.8918 & 0.2166 & 0.93 & 0.96 \\
200 & 1.554 & 0.1272 & 0.91 & 0.94 \\
225 & 2.548 & 0.07837 & 0.87 & 0.91 \\
250 & 3.973 & 0.05006 & 0.82 & 0.88 \\
275 & 5.943 & 0.03274 & 0.77 & 0.83 \\
300 & 8.583 & 0.02164 & 0.70 & 0.77 \\
325 & 12.05 & 0.01417 & 0.62 & 0.70 \\
350 & 15.52 & 0.008803 & 0.48 & 0.60 \\
370 & 21.03 & 0.00493 & 0.35 & 0.45 \\
\hline
\end{tabular}

Table 1 reports computed results to near the critical point of water. In this case the model was unable to compute results above $370^{\circ} \mathrm{C}$. The failure manifested itself as an iteration failure of the solver. However, the root problem was the interaction between the vapor pressure and the EOS. One of the strengths of EOS's is that they are able to estimate parameters near and through critical points. However, this is only true if all 
the properties are obtained from the EOS. In this case the vapor pressure is obtained from a data table. As a result, near the critical point the solution of Eqn. (14) for the compressibility exhibits a discontinuity essentially at the critical temperature $\left(374^{\circ} \mathrm{C}\right)$. Below this temperature there are three real roots to Eqn. (14). The desired root is the largest of these roots. However, near $374^{\circ} \mathrm{C}$ the solution of Eqn. (14) switches to a region in which there is only one real root and this root is associated with the liquid phase $(\mathrm{Z}=0.15)$. Consequently, the solution fails at this point. This same situation can occur with components other than water and will vary depending on the type of vapor pressure correlation used.

\section{Pure Vapor Liquid Equilibrium Examples}

This subsection includes calculations for a number of systems in which only vapor liquid equilibrium are considered. No reactions are occurring and only one liquid phase is present.

Water/Nitrogen. ACS was used to compute the behavior of a system containing only water and nitrogen. Nitrogen was considered an insoluble gas and the Redlich-Kwong EOS was used to compute vapor fugacities. The system volume was assumed to be $0.00135 \mathrm{~m}^{3}$ and $0.03 \mathrm{~kg}$ (1.67 moles) of water and 0.0033 moles of nitrogen were present. Computed pressure and vapor fraction for water are shown in Fig. 1. At the higher temperatures nearly half the water is computed to be in the vapor phase.

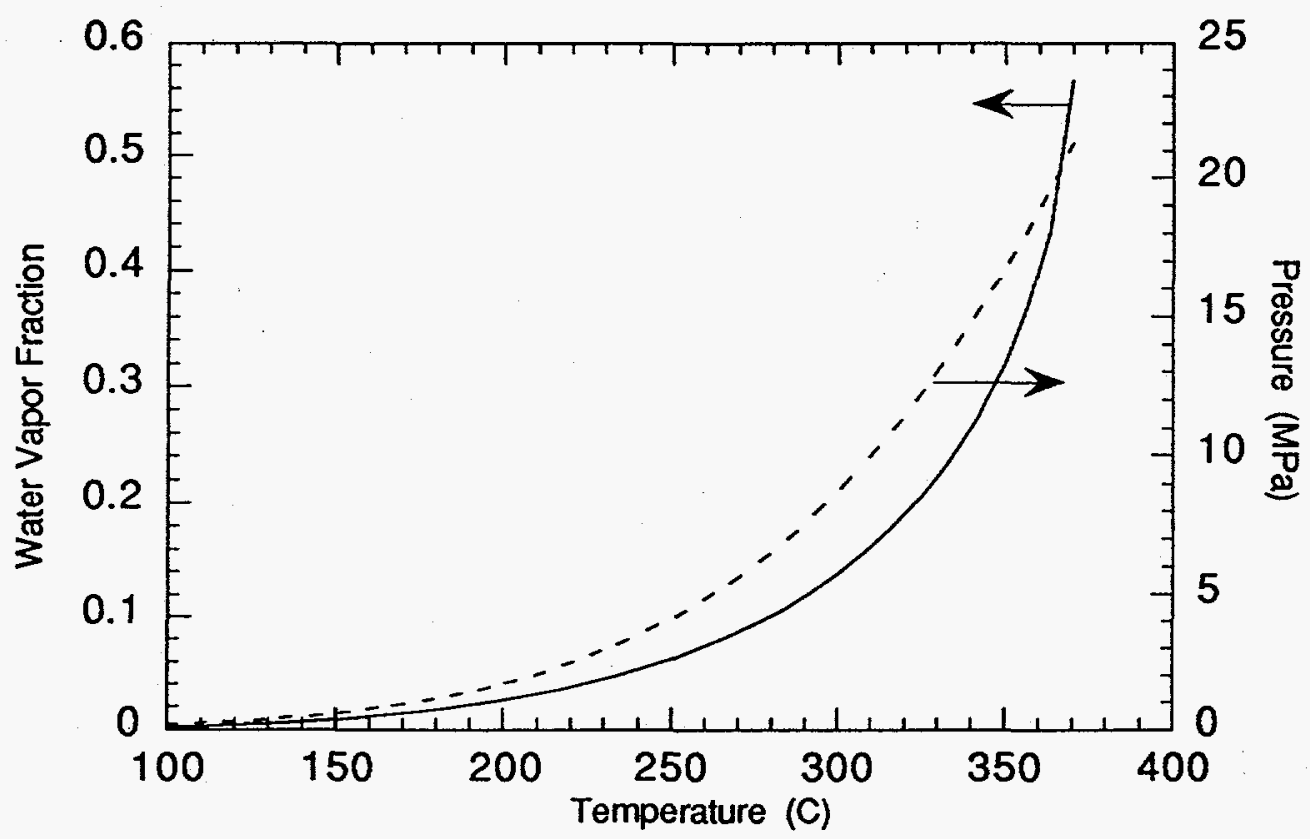

Figure 1. Computed system pressure and molar vapor fraction of water in a simple water nitrogen system. 
Results from this same calculation were compared to values computed by the commercial process simulator ASPEN. Two property options were used in ASPEN, and computations were done with and without ASPEN's free-water option. ASPEN has the ability to consider a free-water phase in an organic/water system along the lines described above for the ACS model. Although no organic liquid exists in this simulation many of the systems of interest to the author do contain oil phases and the inherent performance of the ASPEN simulator with and without the free water option was of interest. Two of the ASPEN property option sets used were also selected because of their ability to handle oil-containing systems. The ASPEN IDEAL data set uses ideal gas behavior and Antoine vapor pressure correlations. The PSRK property option is based on Soave-Redlich-Kwong EOS. The PRMHV2 is based on the PengRobinson-HHV2 EOS models, which is an extension of the basic Peng-Robinson EOS.

ACS and ASPEN results are compared at selected temperatures in Table 2. The ASPEN calculations where performed using a flash operation in which the inlet flow was set at the same ratio as the initial conditions of the ACS model and the outlet condition was set at the computed pressure of the ACS model for each temperature. The comparison in Table 2 is of the number of moles of water in the vapor phase per unit vapor volume. Results for the ACS model are shown for both the EOS model and for the assumption of ideal behavior for the gas phase.

Table 2. Comparison of ACS and ASPEN computed values of water vapor density, several different property set options were uses with the ASPEN model (the * denotes no free-water option, and "na" means not available).

\begin{tabular}{|c|c|c|c|c|c|c|c|c|c|}
\hline \multirow{3}{*}{$\begin{array}{l}\mathrm{T} . \\
\text { (C) }\end{array}$} & \multirow{3}{*}{$\begin{array}{c}\text { System } \\
\text { P } \\
(\mathrm{MPa})\end{array}$} & \multirow{3}{*}{$\begin{array}{c}\text { Water } \\
\text { Vapor } P \\
\text { (MPa) }\end{array}$} & \multicolumn{7}{|c|}{ Water Vapor $\left(\mathrm{mol} / \mathrm{m}^{3}\right)$} \\
\hline & & & \multirow{2}{*}{$\begin{array}{l}\text { ACS } \\
\text { Ideal }\end{array}$} & \multirow{2}{*}{$\begin{array}{l}\text { ACS } \\
\text { EOS }\end{array}$} & \multicolumn{5}{|c|}{ ASPEN } \\
\hline & & & & & IDEAL & PRMHV2 & PRMHV $2^{*}$ & PRSK & PRSK $^{*}$ \\
\hline 100 & 0.201 & 0.101 & 33 & 33 & 33 & 20 & 66 & 33 & 33 \\
\hline 200 & 1.68 & 1.54 & 395 & 424 & 394 & 427 & 463 & 424 & 425 \\
\hline 250 & 4.12 & 3.97 & 914 & 1046 & 913 & na & 1118 & na & 1065 \\
\hline 300 & 8.76 & 8.58 & 1803 & 2342 & 1803 & 2456 & 2518 & na & 2420 . \\
\hline 350 & 16.73 & 16.52 & 3193 & 5359 & 3190 & na & 6005 & na & 5682 \\
\hline 370 & 21.29 & 21.03 & 3938 & 8938 & 3916 & na & na & na & na \\
\hline
\end{tabular}

Not surprisingly, the computed results for ACS and ASPEN agree very well for the ideal gas case. However, the ideal gas assumption breaks down at higher pressures and temperatures and the amount of water in the vapor phase is undoubtedly considerably under predicted at the higher temperatures. The ACS EOS results are reasonably consistent with the ASPEN non-IDEAL results. The ASPEN simulator had difficulty with a number of the conditions and was unable to obtain a converged solution in about one-third of the cases. Part of the ASPEN difficulty was the fact that the conditions were approaching the critical point for water and many general purpose property models have difficulty near critical points. No concerted effort was put into the details of the ASPEN problem. It may well be that with some tuning of parameters the ASPEN model would have been able to obtain a converged solution at more points. 
Crude Oil. One reason for using the relative simple correlations for properties in ACS was to allow it to be used on systems of considerable compositional complexity. Such systems are often handled by defining a set of pseudocomponents which approximates vapor/liquid behavior of the complex system. This approach is especially prevalent in systems containing crude oil. The ASPEN process simulator has a method of defining pseudo-components based on properties of a crude oil. This ability was used to obtain a set of pseudocomponents for a heavy oil. The pseudocomponent properties are listed in Table 3.

Table 3. Properties of pseudocomponents for a heavy crude oil.

\begin{tabular}{|ccccccc|}
\hline Name & $\begin{array}{c}\text { Mole. Wt } \\
\text { (gm/mole) }\end{array}$ & \multicolumn{2}{c}{$\begin{array}{c}\text { Specific } \\
\text { Composition. Gravity }\end{array}$} & $\begin{array}{c}\text { Boiling Pt. } \\
(\mathrm{K})\end{array}$ & $\begin{array}{c}\text { Critical T } \\
(\mathrm{K})\end{array}$ & $\begin{array}{c}\text { Critical P } \\
(\mathrm{MPa})\end{array}$ \\
\hline HNAPH & 142 & $0.87 \%$ & 0.844 & 459 & 660 & 142 \\
KERO & 178 & $5.36 \%$ & 0.877 & 514 & 716 & 178 \\
AGO & 228 & $10.80 \%$ & 0.911 & 577 & 777 & 228 \\
LVGO & 307 & $14.79 \%$ & 0.954 & 661 & 856 & 307 \\
HVGO & 411 & $21.94 \%$ & 1 & 756 & 941 & 411 \\
VR & 540 & $46.08 \%$ & 1.04 & 861 & 1032 & 540 \\
\hline
\end{tabular}

A series of calculation were done with ACS using the pseudocomponent properties listed in Table 3 for a system containing $0.5 \mathrm{~kg}$ of crude oil and having varying total volumes. The computations included a temperature point at $425^{\circ} \mathrm{C}$. The volume was varied to give a variety of computed total pressures at a system temperature of $425^{\circ} \mathrm{C}$. In Fig. 2 the computed mole vapor fraction of all oil components are compared to the same value obtained from the ASPEN model. In the ASPEN calculations, three property set options were used. Two described previously and a third, the BK10 option set, is based on the Braun K10 K-value model. ACS calculations used the boiling point correlation to estimate vapor pressures and the Redlich-Kwong EOS for other vapor properties. Calculations using both the ideal liquid assumption and the HilderbrandScatchard model were done. The ideal liquid results were found to agree best with the ASPEN calculations. Fig. 2 indicates a fairly good agreement between the models.

Hexane-Toluene Computations similar to those for the crude-oil system were done for a system containing hexane and toluene. These are components with known properties. Computed results for total molar volume fraction are compared in Fig. 3. Three different results for the ACS model are plotted: 1) using the Redlich-Kwong EOS and the Hilderbrand-Scatchard models, 2) using the Redlich-Kwong EOS and ideal liquid behavior, 3) ideal behavior both in the gas and liquid phases. In all three cases the boiling point correlation was used to estimate vapor pressures. There is a reasonable spread in the computed results. In this temperature and pressure range the ideal gas and EOS assumptions give very similar results - the ideal gas assumption is valid. Again it would appear that the ideal liquid behavior gives results more consistent with the ASPEN results than the nonideal assumption. Of the ASPEN results those obtained using the BK10 property set are probably most accurate for this system. The ACS results assuming ideal liquid behavior are remarkably close to the ASPEN BK10 results. 


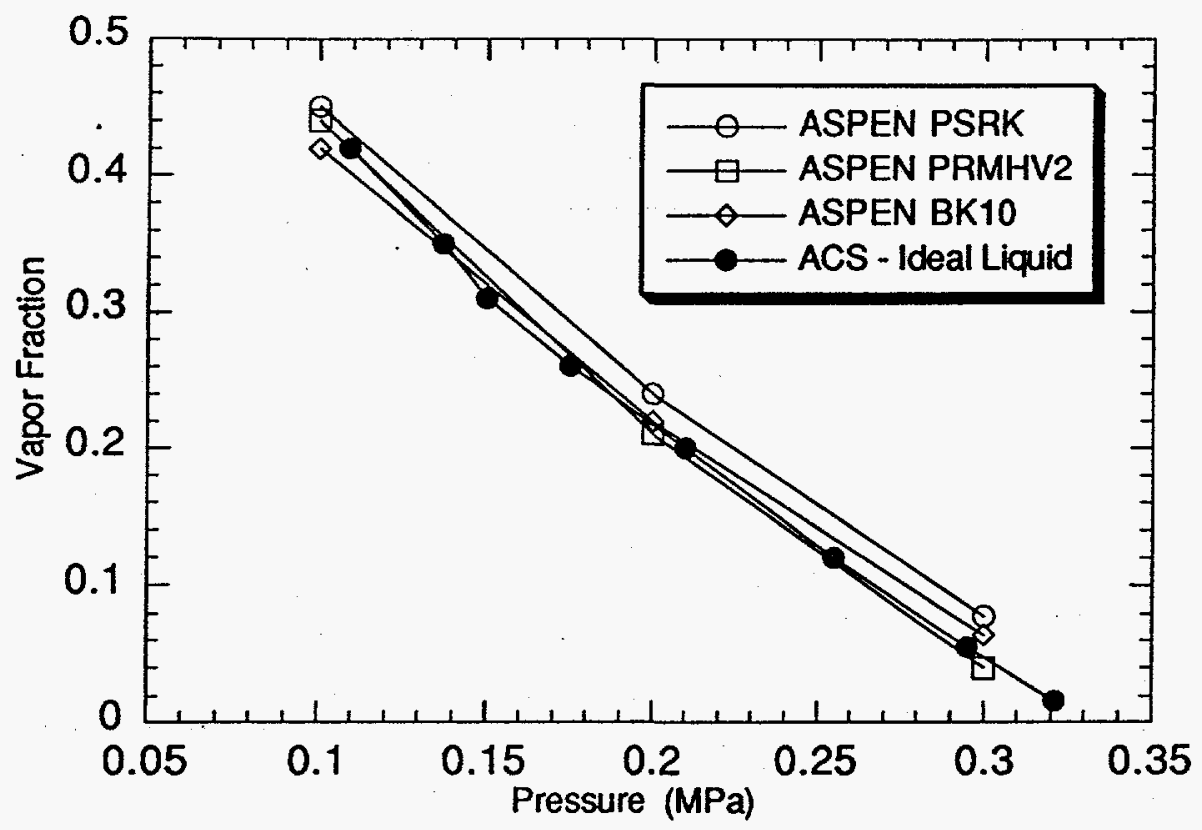

Figure 2. Computed molar vapor fractions of crude oil in systems of varying volume at a temperature of $425^{\circ} \mathrm{C}$.

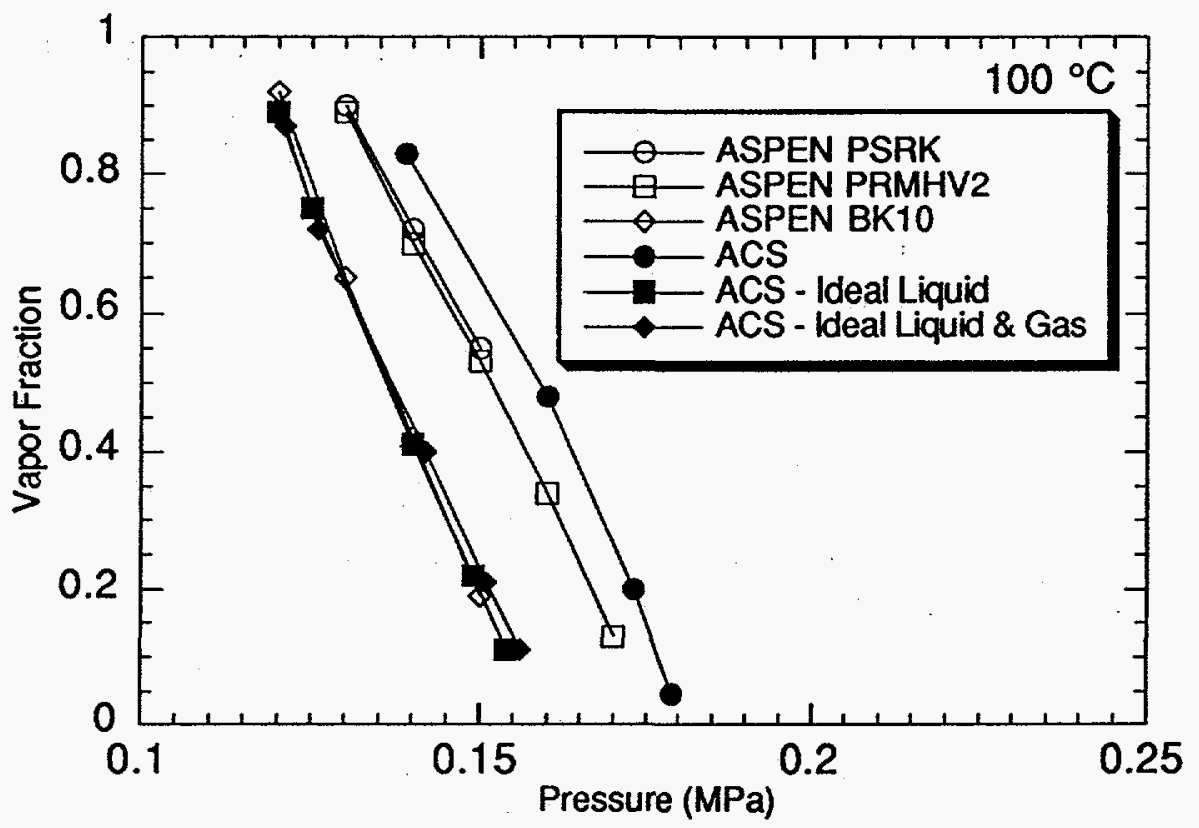

Figure 3. Computed molar vapor fractions for a hexane-toluene systems at a temperature of $100^{\circ} \mathrm{C}$. 
Hexane-Heptadecane. In this series of computations two defined species with fairly widely varying boiling points (hexane, $69^{\circ} \mathrm{C}$; heptadecane, $302^{\circ} \mathrm{C}$ ) were used. Results are compared in Fig. 4. Again, the ACS results using the nonideal liquid model seems to be most inconsistent with the other results. There is a greater difference in the ideal and nonideal gas ACS results with this system than with the hexane-toluene system. The ACS results using the Redlich-Kwong EOS for vapor phase properties and assuming ideal liquid behavior seems to be the most consistent with the ASPEN results. Again the ACS results use vapor pressures estimated from the boiling point correlation.

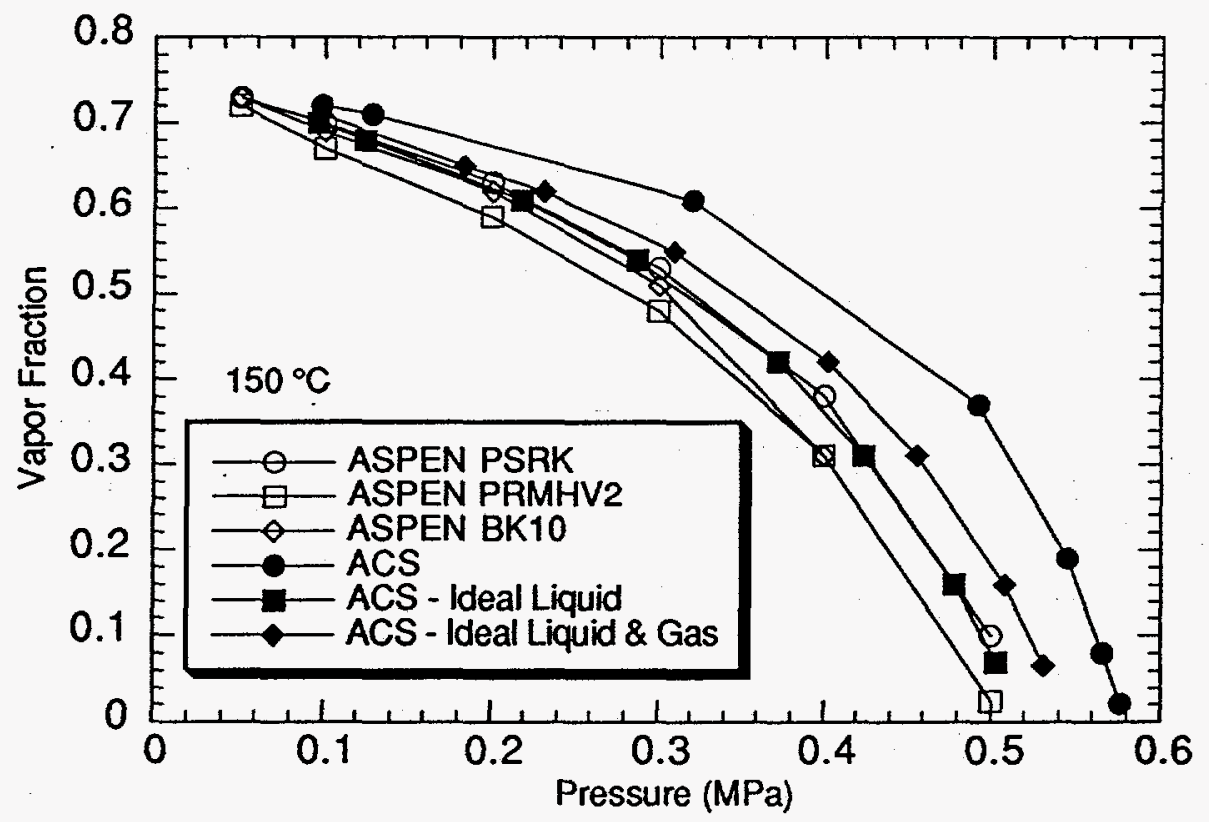

Figure 4. Computed molar vapor fractions for a hexane-heptadecane systems at a temperature of $150^{\circ} \mathrm{C}$.

Water-Carbon Doxide. In a water carbon dioxide system it is often necessary to consider carbon dioxide's solubility in water. Because temperatures of interest usually are above the critical temperature of $\mathrm{CO}_{2}\left(31^{\circ} \mathrm{C}\right)$, a Henry's law formulation is appropriate. Computations using ACS for a water- $\mathrm{CO}_{2}$ system were performed over a temperature range of $177-334^{\circ} \mathrm{C}$. Both the Redlich-Kwong EOS and ideal gas-phase assumption were used for gas phase properties. Ellis and Golding 8 have reported a correlation of Henry's constant for $\mathrm{CO}_{2}$ in water as a function of temperature. These values were used in the ACS model. They also reported raw data for the water- $\mathrm{CO}_{2}$ system. The data consists of $\mathrm{CO}_{2}$ partial pressures and mole fraction of $\mathrm{CO}_{2}$ in the liquid phase. The ACS model was run with ratios of $\mathrm{CO}_{2}$ and water which reproduced the data $\mathrm{CO}_{2}$ partial pressures. In Table 4, the computed liquid-phase mole fraction of $\mathrm{CO}_{2}$ is 
compared to the reported data. Since the model used the Henry's constant developed from the data, it is not surprising that the agreement is fairly good. However, the agreement does indicate that the model is functioning as it should. In this case, the ideal gas assumption matched the data better than the results using the RK EOS. This is probably a result of the way the data was originally reduced to produce the reported Henry's constants. Note that only selected data is available. It is probable that the computed results would do a better job than the ideal gas assumption in matching total molar vapor fractions if they were available.

Table 4 Measured ${ }^{8}$ and computed $\mathrm{CO}_{2}$ gas phase mole fractions.

\begin{tabular}{|c|c|c|c|c|}
\hline \multirow[b]{2}{*}{$\begin{array}{c}T \\
\left({ }^{\circ} \mathrm{C}\right)\end{array}$} & \multirow{2}{*}{$\begin{array}{c}\mathrm{CO}_{2} \\
\text { Partial } \\
\text { Pressure } \\
\text { (MPa) }\end{array}$} & \multicolumn{3}{|c|}{ Gas Phase $\mathrm{CO}_{2}$ Mole Fraction } \\
\hline & & Data & $\begin{array}{c}\text { ACS } \\
\text { RK EOS }\end{array}$ & $\begin{array}{c}\text { ACS } \\
\text { Ideal Gas }\end{array}$ \\
\hline 177 & 1.59 & 0.0022 & 0.0022 & 0.0023 \\
\hline 204 & 3.66 & 0.0059 & 0.0054 & 0.0057 \\
\hline 229 & 4.55 & 0.0076 & 0.0073 & 0.0077 \\
\hline 265 & 2.21 & 0.0045 & 0.0043 & 0.0045 \\
\hline 309 & 7.28 & 0.020 & 0.020 & 0.020 \\
\hline 334 & 6.17 & 0.021 & 0.026 & 0.022 \\
\hline
\end{tabular}

\section{Crude Oil-Water System}

In this example a water crude oil-water system is simulated which includes the presence of two liquid phases, a pure water or free-water phase and a predominately oil phase. The same crude oil pseudocomponents as listed previously were used. The initial charge was $0.5 \mathrm{~kg}$ of oil and $0.05 \mathrm{~kg}$ water in a total volume $0.00105 \mathrm{~m}^{3}$. The temperature was ramped up from $25^{\circ} \mathrm{C}$ to $450^{\circ} \mathrm{C}$. ASPEN calculations were run at several selected temperatures using three property set options. The ASPEN calculations used a flash calculation based on the computed total vapor fraction from the ACS calculation. Selected results are plotted in Fig. 5. Some of the ASPEN calculations failed to converge and consequently computed results for all three option sets are not shown at each selected temperature.

Fig. 5 shows ACS results for two computed parameters as a function of system temperature, the system pressure and the ratio of maximum water solubility in the oil to the total water present. Also shown on the figure, for reference, is the vapor pressure of water as a function of temperature. The ACS results indicate the computed system pressure tracks the water vapor pressure curve quite closely until the solubility ratio drops below one. This is the point at which the free-water phase disappears and the computed system pressure begins to drop below the vapor pressure of water. At $400^{\circ} \mathrm{C}$ the computed system pressure is only one-half that of the vapor pressure of water. At this point about half the water is computed to be in vapor phase and half in the liquid phase. The computed activity coefficient of water in the oil is about one half of its value at saturation. 
ASPEN contains an option similar to the simple ACS model for water dissolved in oil. As a result the ASPEN results agree fairly well with those from ACS.

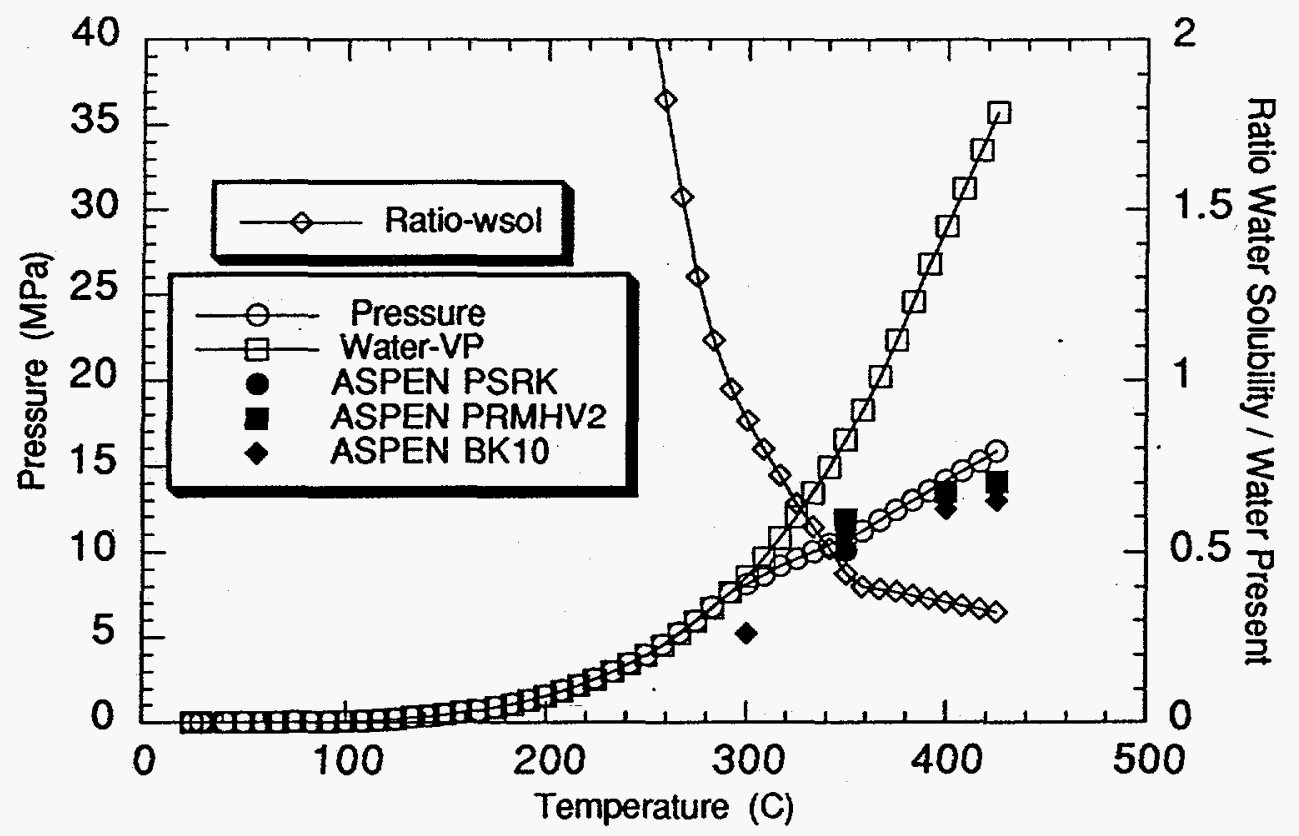

Figure 5. Computed results using the ACS and ASPEN models. ASPEN results are at selected temperatures only while the ACS results are essentially continuous.

\section{A System Including Reaction}

In this example, an autoclave experiment in which biomass was heated in the presence of water was simulated. The system model is based on the assumption that the biomass, assumed to be solid, undergoes a $1^{\text {st }}$ order decomposition reaction to form a new solid, and in the process forms water and carbon dioxide. The stoichiometric ratio of water and carbon dioxide production per unit biomass was assumed to be 10.6 $\mathrm{mol} / \mathrm{kg}$ and $3.72 \mathrm{~mol} / \mathrm{kg}$ respectively. The autoclave had a volume of $0.00135 \mathrm{~m}^{3}$ and was initially loaded at $25^{\circ} \mathrm{C}$ with $0.015 \mathrm{~kg}$ of biomass and $0.03 \mathrm{~kg}$ of water. The initial pressure of the system was $0.101 \mathrm{MPa}$ with air forming the bulk of the initial gas in the reactor. The autoclave was heated over the course of about 100 minutes to about $350{ }^{\circ} \mathrm{C}$ and then held at temperature for another 200 minutes. In the ACS model calculations the air was treated as a permanent gas and the carbon dioxide was treated as a Henry's law component.

The time-temperature history was obtained from an actual experimental run. The pressure data from the experiment and selected computed results are shown in Fig. 6. The rate expression used in the single reaction fit was 


$$
\text { rate }=5 \times 10^{7} \exp \left[\frac{-15000}{T}\right][\text { biomass }] .
$$

A slightly better fit is obtained, Fig. 7 , if it is assumed two $1^{\text {st }}$ order reactions are involved in the decomposition, with $40 \%$ obeying the rate equation

$$
\text { rate }=6 \times 10^{9} \exp \left[\frac{-15000}{T}\right]\left[\text { biomass }_{1}\right] .
$$

and $60 \%$ decomposing according to

$$
\text { rate }=1 \times 10^{9} \exp \left[\frac{-20000}{T}\right]\left[\text { biomass }_{2}\right] .
$$

The difference in the $\mathrm{CO}_{2}$ production rate for the two cases is shown in Fig 8.

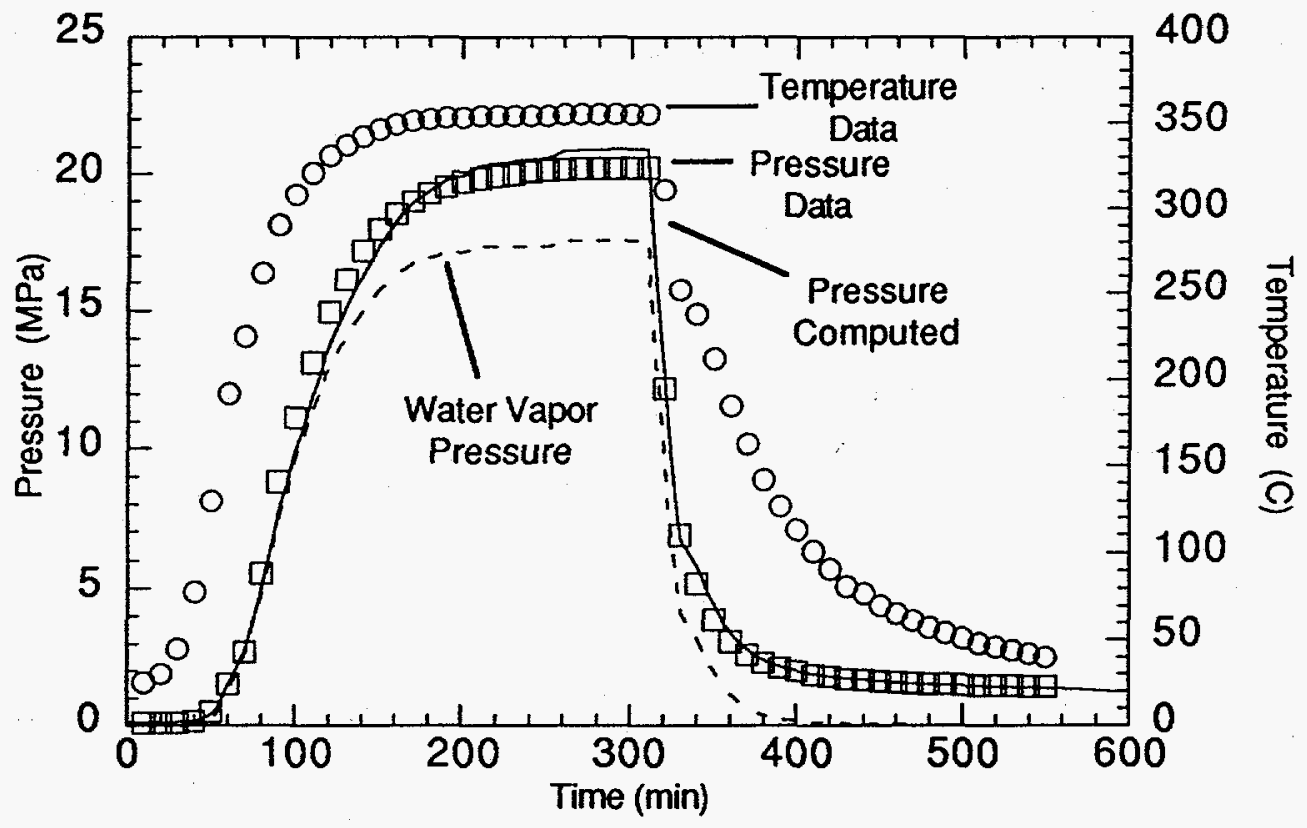

Figure 6. Data and computed pressures for an autoclave experiment with a biomass-water charge using one $1^{\text {st }}$ order decomposition reaction. 


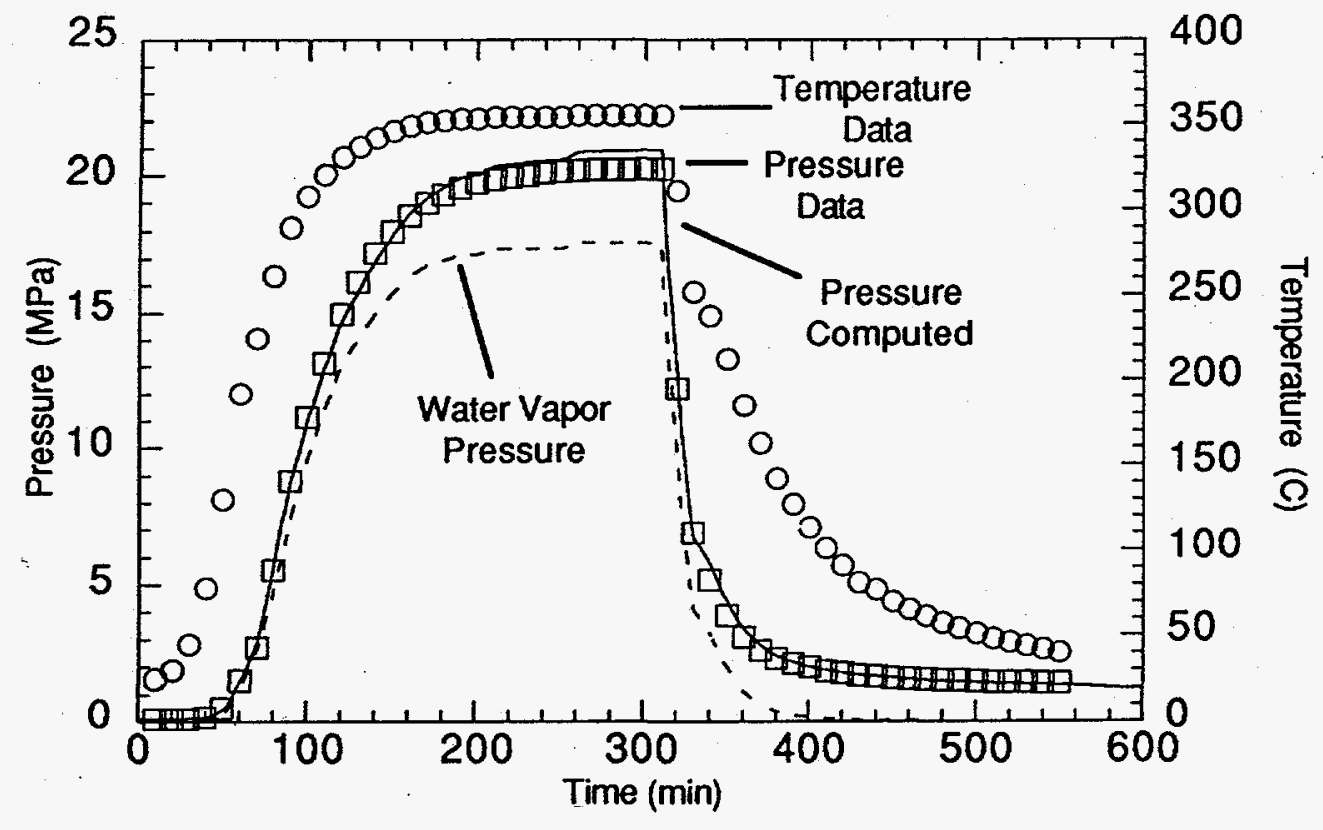

Figure 7. Data and computed pressures for an autoclave experiment with a biomass-water charge using two $1^{\text {st }}$ order decomposition reactions.

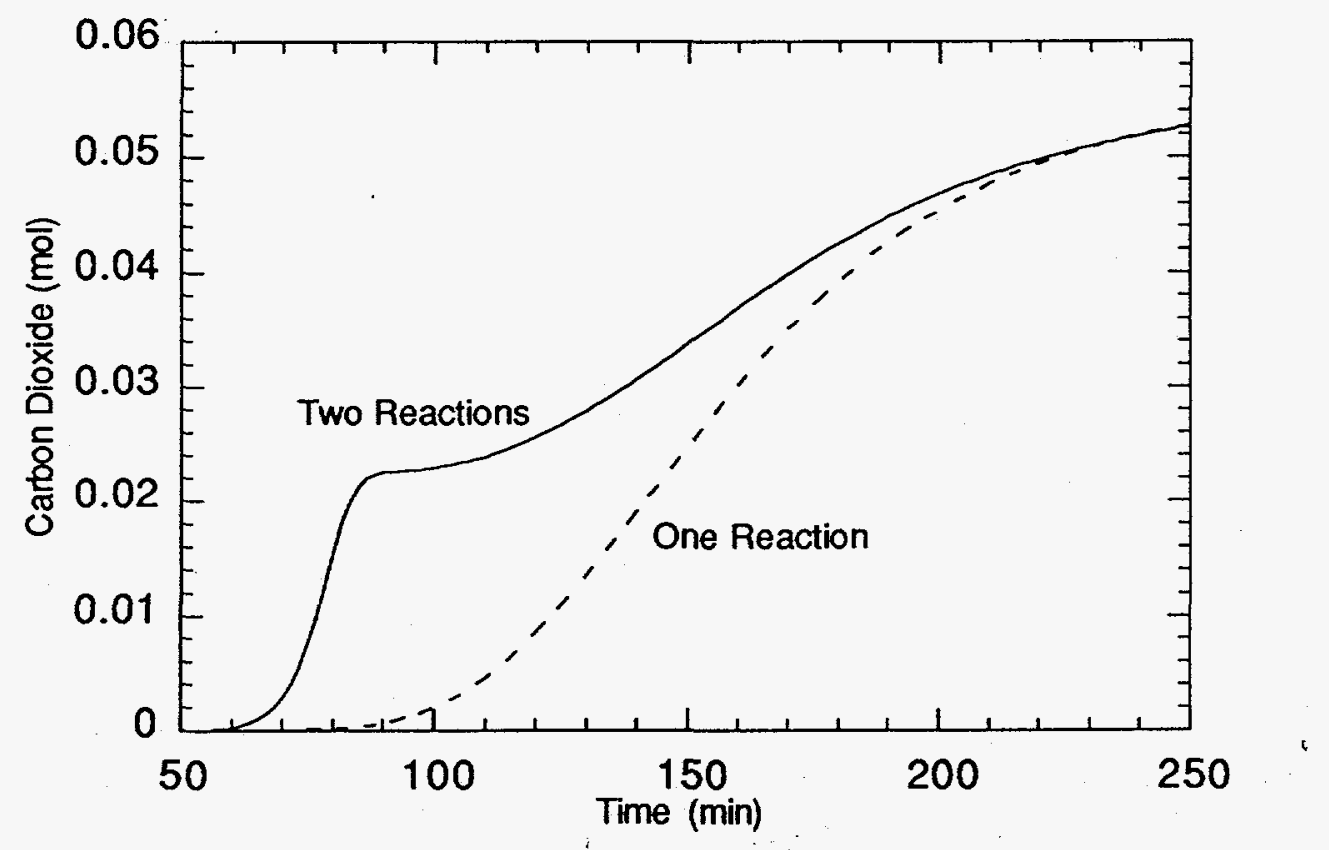

Figure 8. Computed $\mathrm{CO}_{2}$ production for first-order kinetics with two different assumptions on the activation temperature of the decomposition reaction. 
The computed pressure is a function of water vapor pressure, gas production rate and gas solubility. The importance of the water vapor pressure is indicated in Figs. $7 \& 8$ which compare experimental data to the pure water vapor pressure. In Fig. 9, additional results are shown in which calculations were done (assuming two $1^{\text {st }}$ order reactions) for cases in which the produced gas is assumed to be insoluble in the liquid phase. Also included in the figure is the computed pressure in the absence of gas production. The figure indicates that gas production contributes about $2 \mathrm{MPa}$ to the pressure response while $\mathrm{CO}_{2}$ solubility reduces the pressure about $0.7 \mathrm{MPa}$.

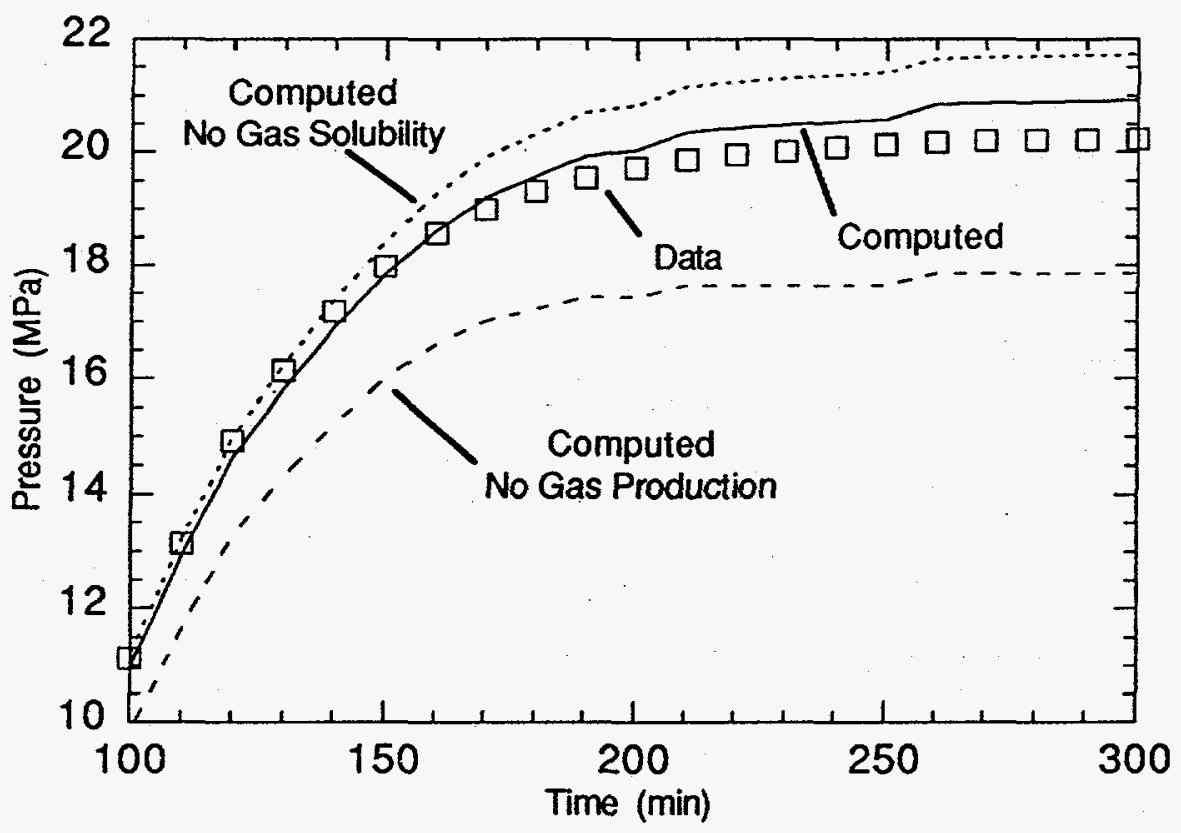

Figure 9. Computed pressure using two $1^{\text {st }}$ order reactions is contrasted to results obtain using the same kinetics but 1) assuming the produced gas is insoluble and 2) assuming no gas production.

\section{Optimization}

The optimization option, which can be employed to help determine problem parameters from fitting of measured pressure data, has been tested for several simple cases. The cases include fits using both one- and two-problem parameters.

Water-Nitrogen System. The first case involved a single parameter optimization for a simple water-nitrogen system which was ramped up in temperature. A fit to pressure data was used to determine the autoclave volume. The test was performed in the following manner. The ACS model was first run assuming an autoclave volume of $0.0001 \mathrm{~m}^{3}$. The computed pressures as a function of time were then entered as "measured" data. The reactor volume was then set to $0.00015 \mathrm{~m}^{3}$ and the optimization 
option was used to search for a volume which best fit the data. The optimization algorithm had no difficulty locating the proper volume with the selected tolerance $(0.1 \%)$. An initial volume guess of 0.0002 was also tried. In this instance the proper volume was also found. However, the procedure required operator intervention. The intervention amounted to setting the error norm to a large value when the solution of the model equations failed because the minimization had selected an unrealistically small volume in its bracketing mode.

Biomass System. The other cases involved a biomass system similar to the one described above. In this case, the ability to determine the kinetic parameters and system volume were explored. As in the first case, an initial run was done to compute pressure data for a given set of kinetic parameters (an activation temperature of $20,000 \mathrm{~K}$ and a preexponential value of $5.0 \times 10^{13}$ ). The generated data to be fit in the optimization test was entered as a series of 12 data points. Eleven of these covered the period of heating and reaction and the last was entered as a final pressure present after the system was cooled back to room temperature.

In the first test the pre-exponential factor was set to a value of $5.0 \times 10^{12}$. The optimization had no difficulty in finding the proper value. This computation took under a minute ( 23 integrations of the base problem were performed) on an HP$9000 / 730$ workstation. In the second test the activation temperature was set to $15,000 \mathrm{~K}$. The proper activation temperature was found with no difficulty. A third test was performed in which the activation temperature was set to $10,000 \mathrm{~K}$. In this case the rate was initially so small that using the default size for the initial offset to find a bracket led to no meaningful change in the error norm which caused difficulty for the bracketing algorithm. Changing the fractional initial step to 0.05 , from the default 0.01 , allowed the optimization scheme to smoothly find the correct activation temperature.

Several test were performed with the biomass system in which two parameters were optimized. In the first test, the pre-exponential kinetic parameter and system volume were offset from the base values, volume from the base of 0.000135 to 0.0002 and the activation temperature from 20,000 to $15,000 \mathrm{~K}$. The optimization was able to find the proper value for both parameters, although nearly 10 minutes of computer time was required. An error tolerance on the error norm of $5 \%$ was used to signal termination. After about 2 minutes of computing, the optimization was fairly near, within $10 \%$, of the true values, reducing the change in error norm to $5 \%$ took the remainder of the computation time. In a second test, the pre-exponential factor was replaced in the optimization by the activation temperature. This two parameter optimization problem also yielded the proper values. In both cases the actual base values were only obtained exactly when the initial search direction was set along the volume axis.

The other two-parameter tests involved the two kinetic parameters, the activation temperature and the pre-xponential factor. This is a severe test of the optimization algorithm because of the highly nonlinear behavior of the activation temperature and the direct interaction of the two parameters. The activation temperature was offset from its base value, $20,000 \mathrm{~K}$, to $15,000 \mathrm{~K}$, and the pre-exponential factor from its base value, 
$5 \times 10^{13}$, to $1 \times 10^{12}$. Several initial search directions were tried. None of the optimization resulted in reaching the base parameters. The results are summarized in Table 5 and show that the optimized activation temperature landed near its true value but the preexponential was considerably below its true value.

Table 5. Optimization results for kinetic parameters using two dimensional search as a function of initial search direction.

\begin{tabular}{|c|c|c|c|c|}
\hline \multicolumn{2}{|c|}{ Direction as Fraction } & \multicolumn{2}{|c|}{ Final Values } & \multirow[b]{2}{*}{ Error $(\mathrm{Pa})$} \\
\hline Act. T. & Pre-exp. & Act. T. (K) & Pre-exp. $(1 / \mathrm{s})$ & \\
\hline Initial Point & $\rightarrow$ & 19,000 & $1 \times 10^{13}$ & $2.9 \times 10^{5}$ \\
\hline 0.05 & 0 & 19,200 & $1 \times 10^{13}$ & $1.9 \times 10^{3}$ \\
\hline 0 & 0.05 & \multicolumn{2}{|c|}{ Failed } & \\
\hline 0.05 & 0.05 & 19,300 & $1.3 \times 10^{13}$ & $1.6 \times 10^{3}$ \\
\hline 0.01 & 0.02 & 19,600 & $2.2 \times 10^{13}$ & $1.0 \times 10^{3}$ \\
\hline Base Point - & $\rightarrow$ & 20,000 & $5.0 \times 10^{14}$ & 0 \\
\hline
\end{tabular}

\section{SUMMARY}

A model has been developed to help obtain additional information from autoclave reactor experiments - beyond that available for examining the final products and raw system pressure data. The model was implemented in a FORTRAN computer code which solves the highly nonlinear differential/algebraic equation system. The model was constructed to allow a wide variety of chemical species to be included. Both vapor liquid equilibrium and chemical changes resulting from reaction are considered. The current model uses relatively simple relations for fugacity calculations needed to compute the vapor/liquid equilibria present, but the modular nature of the computer code and the powerful algorithm used to solve the DAE system should allow more sophisticated property models to be incorporated as desired.

The computer implementation was formulated to allow pressure matching of autoclave experiments. Provisions are included in the code to allow optimization routines to assist in achieving fits of the pressure data by manipulation of many model parameters. Computer running times for most systems tested to date has been under one minute on an HP-9000/730 workstation for a complete solution. Optimization runs, which require many model solutions can require 10 minutes or more for two dimensional optimizations.

Selected model results for a number of test problems have been found to be consistent with results obtained using the commercial ASPEN process simulator and with $\mathrm{CO}_{2}$ water data at elevated temperatures. 


\section{REFERENCES}

1. R.C. Reid, J.M. Prauznitz, T.K. Sherwood, The Properties of Gases and Liquids, Third Edition, (McGraw-Hill Book Company, New York, 1977) pp. 37-40, 75-78, 171-177, 294-295.

2. R.C. Reid, J.M. Prauznitz, B.E. Poling, The Properties of Gases and Liquids, Fourth Edition, (McGraw-Hill Book Company, New York, 1987) pp. 97-101, 143-145, 220, 284-286.

3. T.F. Irvine, Jr. and J.P. Hartnett, Steam and Air Tables in SI Units , (Hemisphere Publishing Corporation, Washington, 1976).

4. A.C. Hindmarsh and L.R. Petzold, "Algorithms and Software for Ordinary Differential Equations and Differential/Algebraic Equations, Part II: Higher Order Methods and Software Packages", Computers in Physics, Vol.9 No.2. 34-41 (March/April 1995).

5. P.N. Brown, A.C. Hindmarsh and L.R. Petzold, "Consistent Initial Condition Calculation for Differential-Algebraic Systems", Lawrence Livermore National Laboratory, Livermore, Calif., UCRL-JC-122175 (1995).

6. A.C. Hindmarsh. Private communication (1995).

7. W.H. Press, S.A. Teukolsky, W.T. Vetterling and B.P. Flannery, Numerical Recipes in FORTRAN, The Art of Scientific Computing, Second Edition (Cambridge University Press, Cambridge), pp. 178-180, 387-395, 406-413.

8. A.J. Ellis and R.M. Golding, "The Solubility of Carbon Dioxide above $100^{\circ} \mathrm{C}$ in Water and in Sodium Chloride Solutions", American Journal of Science, 261, 47-60, (1963). 
NOMENCLATURE

a Parameter in the Redlich-Kwong EOS

$\left(\mathrm{Pa} \cdot \mathrm{m}^{6} \cdot{ }^{\circ} \mathrm{K}^{0.5} / \mathrm{mol}^{2}\right)$

$\mathcal{A}$ Parameter in Antoine vapor pressure correlation

$a_{i j} \quad$ Mixture terms in fugacity coefficient Eqn. (12)

$\left(\mathrm{Pa} \cdot \mathrm{m}^{6 .}{ }^{\circ} \mathrm{K}^{0.5} / \mathrm{mol}^{2}\right)$

$A^{*} \quad$ Parameter in compressibility form of Redlich-Kwong EOS

$b$ Parameter in the Redlich-Kwong EOS

$\left(\mathrm{m}^{3}\right)$

$\mathcal{B}$ Parameter in Antoine vapor pressure correlation

$B^{*} \quad$ Parameter in compressibility form of Redlich-Kwong EOS

C Parameter in Antoine vapor pressure correlation

$f_{i}^{L} \quad$ Fugacity of component $i$ in the liquid phase

$f_{i}^{V} \quad$ Fugacity of component $i$ in the vapor phase

$f_{i}^{\circ} \quad$ Standard-state fugacity of component $i$

$H_{i} \quad$ Henry's law constant for component $i$

(Pa)

$m_{w_{i}} \quad$ Mass of component $i$ per mol

$(\mathrm{kg} / \mathrm{mol})$

$M_{i} \quad$ Amount of species $i$

( $\mathrm{kg}$ or $\mathrm{mol}$ )

$n_{r} \quad$ The number of reactions

$P \quad$ Pressure

(Pa)

$P_{c} \quad$ Critical pressure

$P_{c_{m}} \quad$ Critical pressure of a mixture

$P_{v p i} \quad$ Vapor pressure of component $i$

$P_{r} \quad$ Reduced pressure

$r_{n} \quad$ The rate of reaction $n$

$(\mathrm{kg} / \mathrm{s}$ or $\mathrm{mol} / \mathrm{s})$

$R \quad$ Gas constant, 8.314

$\left(\mathrm{Pa} \cdot \mathrm{m}^{3} / \mathrm{mol}^{\circ} \cdot \mathrm{K}\right)$

$R_{i} \quad$ Residual for equation $i$

$t$ Time

(s)

$T$ Temperature

$T_{c} \quad$ Critical temperature

$T_{c_{m}} \quad$ Critical temperature of a mixture

$T_{r} \quad$ Reduced temperature

$v_{L} \quad$ Liquid phase volume

$\left(\mathrm{m}^{3}\right)$

$v_{s} \quad$ Solid phase volume

$\left(\mathrm{m}^{3}\right)$

$v_{T} \quad$ Total volume

$\left(\mathrm{m}^{3}\right)$

$V$. Gas molar volume

$\left(\mathrm{m}^{3} / \mathrm{mol}\right)$

$V_{i}^{L} \quad$ Liquid molar volume of component $i$

$\left(\mathrm{m}^{3} / \mathrm{mol}\right)$

$x_{1}^{s} \quad$ Mole fraction of water at saturation in organic liquid 
$x_{i} \quad$ Mole fraction of component $i$ in the liquid phase

$y_{i} \quad$ Mole fraction of component $i$ in the gas phase

$Y_{v_{i}} \quad$ Vapor fraction of component $i$

$\mathrm{Z} \quad$ Compressibility factor

$\alpha_{i n}$ The stoichiometric coefficient of component

$i$ in reaction $n$

$\bar{\delta} \quad$ Average solubility parameter of component $i$ in activity coefficient model

$\delta_{i} \quad$ Solubility parameter of component $i$ in activity coefficient model $\quad(\mathrm{Pa})$

$\Delta H_{v_{i}}$ Molar enthalpy of vaporization of component $i$

$\Delta U_{i} \quad$ Energy required isothermally to evaporate liquid component $i$ from saturated liquid to ideal gas

$(\mathrm{J} / \mathrm{mol})$

$\phi_{i} \quad$ Gas-phase fugacity coefficient of component $i$

$\phi_{i}^{s} \quad$ Gas-phase fugacity coefficient of component $i$ at saturation

$\gamma_{i} \quad$ Liquid-phase activity coefficient of component $i$

$\omega_{i} \quad$ Pitzer's acentric factor for component $i$ 